\title{
Effect of the ABO blood groups on the development, clinical features and survival of multiple myeloma
}

\author{
Mesut Göçer · Erdal Kurtoğlu
}

Received: 14 October 2020 / Accepted: 2 December 2020 / Published online: 23 December 2020

(C) Springer-Verlag GmbH Austria, part of Springer Nature 2020

\begin{abstract}
Summary
Background Multiple myeloma (MM) is a cytogenetically heterogeneous and incurable plasma cell disease with unknown etiology. It is thought that the $\mathrm{ABO}$ blood groups may play a role in the etiology of many diseases. The purpose of this study is to determine whether there is a relationship between the ABO blood groups and the development of MM, clinical findings and overall survival.

Methods In this single-center, retrospective and observational study, 198 patients with known blood types who diagnosed with MM between January 2012 and June 2020 were included.

Results It was shown that individuals with blood group 0 had a significantly lower risk of $\mathrm{MM}(\mathrm{OR}=$ $0.575,95 \%$ confidence interval $0.416-0.794, P=0.001$ ). The incidence of extramedullary lesion was significantly higher in those with 0 blood group compared to other blood groups $(P=0.000)$. Overall survival was significantly shorter in patients with 0 blood group than those without 0 blood group $(P=0.007)$.

Conclusion Individuals with 0 blood group had a lower risk of developing MM. It was determined that having 0 blood group is a predisposing factor for the development of extramedullary lesion in MM patients. However, it was shown that having a blood group of 0 was a very significant prognostic factor for MM patients and was associated with short OS.
\end{abstract}

Keywords ABO blood group - Multiple myeloma . Survival $\cdot$ Extramedullary lesion $\cdot$ Prognostic factor

M. Göçer, M.D (西) · E. Kurtoğlu

Department of Internal Medicine, Division of Hematology,

Antalya Training and Research Hospital, 07100 Antalya,

Turkey

gocermesut@gmail.com

\section{Introduction}

Multiple myeloma (MM) is a cytogenetically heterogeneous and incurable plasma cell disease characterized by clonal proliferation of malignant plasma cells [1]. It accounts for approximately $10 \%$ of all hematological malignancies [2]. MM is generally seen in older ages and is more common in men [1]. Although the etiology of MM is not fully known, smoking, alcohol, diet, obesity, radiation and benzene exposure, chronic antigenic stimulation and genetic factors are thought to play a role [3]. Patients may present with various symptoms and signs such as anemia, low back pain, osteolytic lesions, extramedullary lesion, elevated creatinine, and hypercalcemia $[4,5]$. As the etiology of the disease is unknown, it cannot be predicted which clinical symptoms will occur in which patient. Overall survival (OS) continues to increase with current treatments.

$\mathrm{ABO}$ blood groups is the most important and most antigenic of blood group systems [6]. The ABO blood group system, defined in 1900, is classified according to the presence or absence of antigens $A$ and $B$ in carbohydrate structures expressed on the surface of erythrocytes [7]. Apart from the erythrocyte surface, these antigens can also be expressed on the surface of many human cells and tissues such as neurons, epithelial cells, platelets, vascular endothelium and body fluids $[8,9]$. However, the distribution of ABO blood groups may vary based on various ethnic, geographical and socioeconomic group [10].

It is thought that ABO blood groups may play a role in the etiology of many diseases or determine the clinical behavior. A recent study has shown that patients with blood group A have a higher risk of hospitalization following severe acute respiratory syndrome coronavirus 2 (SARS-CoV-2) infection, while patients with blood group 0 have a lower risk [11]. 
In several previous studies, the relationship between many cancer, especially gastric and pancreatic cancer, and the ABO blood group system has been demonstrated [12-14]. In addition to solid organ tumors, it has been shown that there is a relationship between Hodgkin lymphoma, a hematological malignancy, and $B$ blood group, and a relationship between acute lymphoblastic leukemia and blood group 0 [15]. In addition to all these, another study has shown that $\mathrm{ABO}$ blood groups is a risk factor for malignancy development and also has an effect on the prognosis of malignancy [16].

The purpose of this study is to determine whether there is a relationship between the ABO blood group system and the development of MM. Another purpose of this study is to determine the correlation between ABO blood group system and clinical findings of the disease and whether there is a relationship between ABO blood group system and overall survival.

\section{Materials and methods}

\section{Patients}

This single-center, retrospective and observational study included 198 patients with known blood types who were newly diagnosed with multiple myeloma between January 2012 and June 2020. If the patients were eligible for autologous stem cell transplantation, patients diagnosed before 2016 were given VAD (bortezomib, adriamycin and dexamethasone) or Veldex (bortezomib and dexamethasone) treatment protocols in the first step, while PAD (bortezomib, adriamycin and dexamethasone) or VCD (bortezomib, cyclophosphamide and dexamethasone) treatment protocols were given at the first step to those diagnosed after 2016. A total of 92 patients underwent autologous stem cell transplantation. Vel-dex (bortezomib and dexamethasone), lenalidomide or melphalan were given to patients who were not eligible for transplant.

The control group included all patients who presented to the hematology outpatient clinic between June 2019 and June 2020, who did not have any known malignancies and whose blood groups were registered in the hospital system.

In addition to the blood types of the patients, clinical findings and laboratory data at the time of diagnosis were examined. Magnetic resonance imaging (MRI) and/or positron emission tomography-computed tomography (PET-CT) was required to detect the presence of lytic lesion and extramedullary lesion. An extramedullary lesion was defined as the presence of plasma cell tumor presenting either as a soft tissue mass spreading from the bone or in extraosseous organs other than the bone marrow. Patients who also developed an extramedullary lesion during their follow-up were included in the study. Patients who had solitary extramedullary lesions or did not meet MM diagnostic criteria were not included in the study.

The primary endpoint of the study was to determine whether blood groups contributed to the development of MM by comparing the blood groups of the patients and the control group. The secondary endpoint was to examine whether there was a relationship between blood groups and clinical findings and overall survival.

Approval was obtained from the hospital administration and the local ethics committee to use the patients' data. The study was conducted in accordance with the ethical principles of the Declaration of Helsinki.

\section{Statistical analysis}

Relationships between two categorical characteristics were examined using the Pearson Chi-square test or Fisher's exact test. Changes in numerical characteristics were analyzed using the independent samples t-test for data with normal distribution and the Mann-Whitney $U$ test for data without normal distribution. Binary logistic regression model was used to analyze statistically significant parameters in the univariate analysis. The effect of blood groups on overall survival times was compared using logrank test and a Kaplan-Meier plot was drawn. Factors affecting overall survival (OS) duration were analyzed using the multiple Cox regression model. SPSS 22.0 software (IBM SPSS Statistics 22, IBM Corporation, Chicago, USA) was used in calculations and $P<0.05$ was accepted as the statistical significance level.

\section{Results}

A total of 198 patients (92 [46.5\%] women and 106 [53.5\%] men) with a diagnosis of MM who were followed in our clinic and whose blood types were accurately registered in the hospital system were included in our study. The median age of all patients was 63 (32-90) years. Group A comprised 92 (46.5\%) patients: $49(24.7 \%)$ were group 0, 38 (19.2\%) were group B and 19 (9.6\%) were group AB.

The control group was comprised of 23,558 individuals who presented to hematology outpatient clinics and did not have any known malignancy. In this population, the frequency of blood group A was $41.1 \%$, the frequency of blood group 0 was $36.4 \%$, the frequency of blood group B was $15.8 \%$ and the frequency of blood group $\mathrm{AB}$ was $6.8 \%$. Compared to the control group, the results showed that individuals with 0 blood group had a significantly lower risk of MM (odds ratio $[\mathrm{OR}]=0.575,95 \%$ confidence interval [Cl] 0.416-0.794, $P=0.001$ ). There was no significant increase or decrease in risk for MM in other blood groups (Table 1).

The demographic and clinical characteristics of the patients according to their blood groups are sum- 
Table 1 Association between $\mathrm{ABO}$ blood groups and risk of multiple myeloma development

\begin{tabular}{|c|c|c|c|c|c|}
\hline Blood group & Patient $n(\%)$ & Control $n(\%)$ & Odds ratio & $95 \%$ confidence interval & $P$ \\
\hline$A$ & $92(46.5)$ & $9680(41.1)$ & 1.244 & $0.940-1.647$ & 0.128 \\
\hline 0 & $49(24.7)$ & 8575 (36.4) & 0.575 & $0.416-0.794$ & 0.001 \\
\hline$B$ & $38(19.2)$ & $3712(15.8)$ & 1.270 & $0.890-1.812$ & 0.201 \\
\hline$A B$ & $19(9.6)$ & $1591(6.8)$ & 0.682 & $0.424-1.098$ & 0.117 \\
\hline Total & $198(100)$ & $23,558(100)$ & - & - & - \\
\hline
\end{tabular}

marized in Table 2. First of all, patients in the four different blood groups were compared with each other. Following this, patients with any blood group were individually compared with patients who did not have that blood group. The percentage of women in only blood group A was higher than the percentage of men $(53.3 \% / 46.7 \%)$. However, there was no significant difference in gender distribution between the groups $(P=0.121)$. There was no significant difference between the groups in terms of median age at the time of diagnosis $(P=0.548)$ The heavy chain and light chain types of the patients were evaluated. It was found that immunoglobulin A type heavy chain and kappa type light chain was more common in patients with blood group A compared to the other groups $(P=0.021$ and $P=0.032$, respectively). Serum lactate dehydrogenase (LDH) level was significantly higher in the blood group 0 compared to the other blood groups $(P=0.007)$. There was no significant difference between the median values of $\beta-2$ microglobulin levels in all blood groups $(P=0.654)$.

Correlations between blood types and clinical signs of multiple myeloma, such as hypercalcemia, renal failure, anemia and bone lesions (CRAB), were evaluated. Calcium elevation was defined as serum calcium level $>11 \mathrm{mg} / \mathrm{dL}$, and there was no difference in hypercalcemia between blood groups $(P=0.509)$. Serum creatinine level $>2 \mathrm{mg} / \mathrm{dL}$ was defined as renal failure, and there was no significant difference between blood groups $(P=0.163)$. Anemia was defined

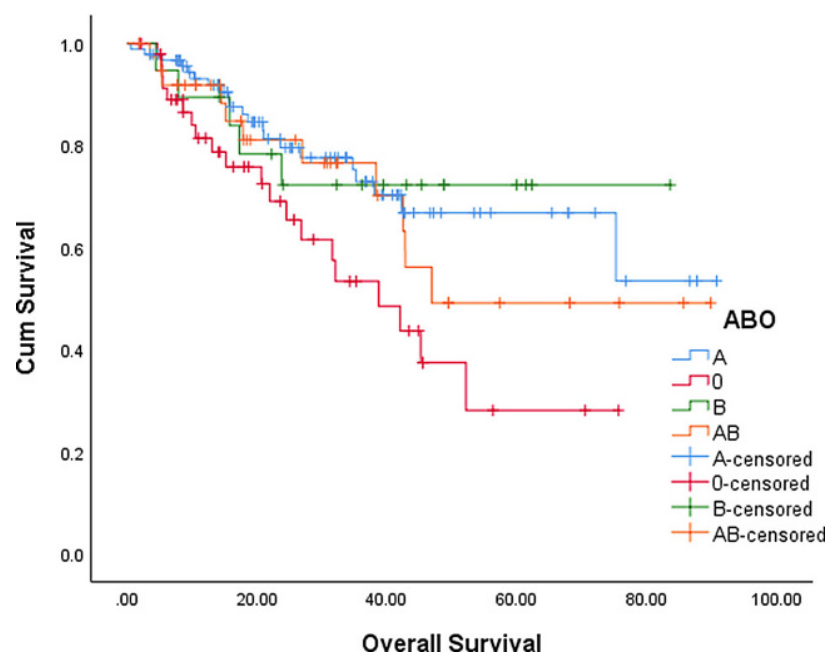

Fig. 1 Overall survival curves of multiple myeloma patients according to blood groups $A, 0, B$ and $A B$ as hemoglobin level below the lower limit of normal $(2 \mathrm{~g} / \mathrm{dL})$ or hemoglobin level $<10 \mathrm{~g} / \mathrm{dL}$. There was no difference in anemia between blood groups $(P=0.363)$. Patients were evaluated for bone lesions specific to multiple myeloma. There was no significant difference in lytic lesions between blood groups $(P=0.637)$. The incidence of extramedullary lesion in the entire patient population was $15.1 \%$. There was a significant difference in the incidence of extramedullary lesion between blood groups $(P=0.000)$. The incidence of extramedullary lesion was the lowest in blood group B with $7.9 \%$ and the highest in blood group 0 with $34.7 \%$. The incidence of extramedullary lesion was significantly higher in patients with blood group 0 based on the comparison of patients with blood group 0 and those with non- 0 blood groups (A, $\mathrm{B}$ and $\mathrm{AB} ; P=0.000$ ).

The relationship between blood groups and overall survival (OS) was evaluated. OS curves of the patients were drawn based on their blood groups. There was a borderline significant difference between blood groups ( $P=0.047$; Fig. 1). All blood groups were evaluated individually to determine the blood group that caused this difference. When the blood groups were evaluated individually, overall survival was significantly shorter in patients with blood group 0 than those with non-0 blood groups ( $\mathrm{A}, \mathrm{B}$ and $\mathrm{AB} ; P=0.007)$. OS curves of MM patients with blood group 0 and those with non-0 blood groups (A, B and $A B$ ) are shown in Fig. 2. In multivariate analyzes, age $(P=$

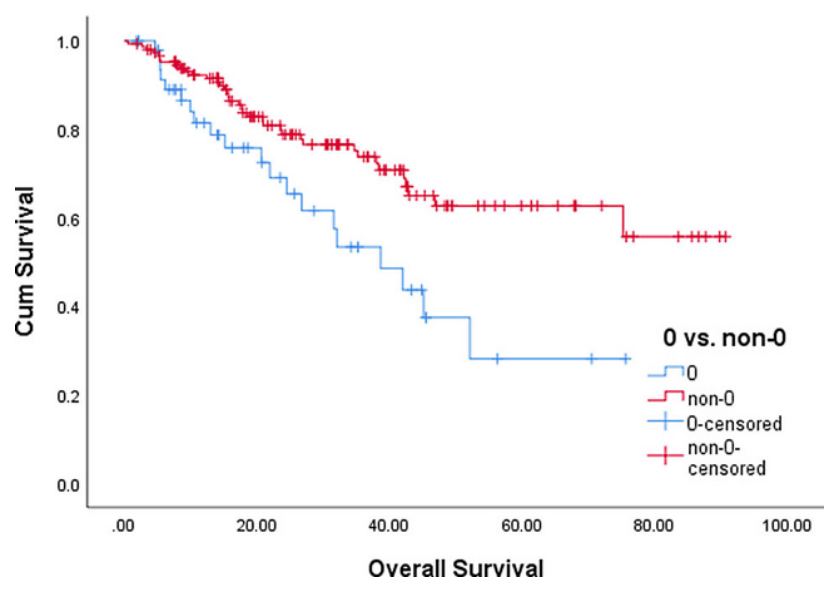

Fig. 2 Overall survival curves of multiple myeloma patients according to blood groups 0 and non- 0 (A, B and $A B)$ 
Table 2 Demographic and clinical characteristics of patients diagnosed with multiple myeloma according to blood groups

\begin{tabular}{|c|c|c|c|c|c|c|c|c|c|}
\hline Clinical features & $\mathrm{A}(n=92)$ & $0(n=49)$ & $\mathrm{B}(n=38)$ & $\mathrm{AB}(n=19)$ & $P$ & $\begin{array}{l}P A \\
\text { vs. non-A }\end{array}$ & $\begin{array}{l}P 0 \\
\text { vs. non-0 }\end{array}$ & $\begin{array}{l}P B \\
\text { vs. non-B }\end{array}$ & $\begin{array}{l}P A B \text { vs. non- } \\
A B\end{array}$ \\
\hline $\begin{array}{l}\text { Gender F/M n/n, } \\
(\% / \%)\end{array}$ & $\begin{array}{l}49 / 43 \\
(53.3 / 46.7)\end{array}$ & $\begin{array}{l}24 / 25 \\
(49.0 / 51.0)\end{array}$ & $\begin{array}{l}13 / 25 \\
(34.2 / 65.8)\end{array}$ & $\begin{array}{l}6 / 13 \\
(31.6 / 68.4)\end{array}$ & 0.121 & 0.087 & 0.742 & 0.105 & 0.228 \\
\hline $\begin{array}{l}\text { Age med. at the time } \\
\text { of diagnosis }\end{array}$ & $62(36-90)$ & $63(32-87)$ & $66(41-79)$ & $62(41-79)$ & 0.548 & 0.636 & 0.809 & 0.166 & 0.487 \\
\hline $\begin{array}{l}\text { Heavy chain type } n \\
\text { (\%) }\end{array}$ & - & - & - & - & 0.039 & 0.021 & 0.379 & 0.277 & 0.479 \\
\hline$G$ & $50(54.3)$ & $24(49.0)$ & 26 (68.4) & $11(57.9)$ & - & - & - & - & - \\
\hline$A$ & $32(34.8)$ & $14(28.6)$ & $4(10.5)$ & $2(10.5)$ & - & - & - & - & - \\
\hline$M$ & $0(0)$ & $1(2.0)$ & $0(0.0)$ & $0(0.0)$ & - & - & - & - & - \\
\hline Non-G, $A, M$ & $10(10.9)$ & $10(20.4)$ & $8(21.1)$ & $6(31.6)$ & - & - & - & - & - \\
\hline Light chain type $n(\%)$ & & - & - & - & 0.048 & 0.032 & 0.059 & 0.748 & 0.092 \\
\hline K & $59(64.1)$ & $20(40.8)$ & $22(57.9)$ & $8(42.1)$ & - & - & - & - & - \\
\hline$L$ & $33(35.9)$ & $28(57.1)$ & $16(42.1)$ & $10(52.6)$ & - & - & - & - & - \\
\hline Non-K, $L$ & $0(0.0)$ & $1(2.1)$ & $0(0.0)$ & $1(5.3)$ & - & - & - & - & - \\
\hline LDH> normal $n(\%)$ & $23(25.0)$ & $23(46.9)$ & $9(23.7)$ & $6(31.6)$ & 0.039 & 0.123 & 0.007 & 0.333 & 1.000 \\
\hline $\begin{array}{l}\text { Beta-2 microglobulin } \\
\text { med }\end{array}$ & $4.69(1.2-59.4)$ & $\begin{array}{l}5.51 \\
(1.51-42.3)\end{array}$ & $4.49(1.8-61.3)$ & $\begin{array}{l}5.64 \\
(1.6-27.3)\end{array}$ & 0.654 & 0.223 & 0.129 & 0.841 & 0.671 \\
\hline Hypercalcemia $n(\%)$ & $11(12.0)$ & $9(18.4)$ & $3(7.9)$ & $3(15.8)$ & 0.509 & 0.679 & 0.227 & 0.424 & 0.721 \\
\hline $\begin{array}{l}\text { Renal Impairment } n \\
\text { (\%) }\end{array}$ & $21(22.8)$ & $17(34.7)$ & $8(21.1)$ & $8(42.1)$ & 0.163 & 0.204 & 0.198 & 0.420 & 0.173 \\
\hline Anemia $n(\%)$ & $64(69.6)$ & $41(83.7)$ & $24(63.2)$ & $15(78.9)$ & 0.363 & 0.403 & 0.132 & 0.271 & 0.789 \\
\hline Lytic lesion $n(\%)$ & $80(87.0)$ & $42(85.7)$ & $30(78.9)$ & 17 (89.5) & 0.637 & 0.688 & 1.000 & 0.211 & 1.000 \\
\hline $\begin{array}{l}\text { Extramedullary lesion } \\
n(\%)\end{array}$ & $8(8.6)$ & $17(34.7)$ & $3(7.9)$ & $2(10.5)$ & 0.000 & 0.082 & 0.000 & 0.305 & 1.000 \\
\hline
\end{tabular}

0.040), LDH level $(P=0.000)$ and beta- 2 microglobulin level $(P=0.042)$ were found to have a significant effect on OS.

\section{Discussion}

We think that defining the potential relationship between ABO blood groups and cancer development is of great importance in terms of public health. If a relationship is determined, this can change the course of cancer screening programs. Based on this, several studies have been conducted on this subject, and a relationship between many cancer types and blood groups has been shown [13-16]. However, it should be noted that the distribution of $\mathrm{ABO}$ blood groups may differ throughout the world population [17]. This study investigated whether ABO blood groups have a role in $\mathrm{MM}$ etiology. In addition, we evaluated the prognostic significance of $\mathrm{ABO}$ blood groups that may affect disease-specific clinical findings and survival.

In previous studies, in addition to solid organ tumors, the association of hematological malignancies such as lymphoma and leukemia with $\mathrm{ABO}$ blood groups was also investigated [15, 18]. In a study, it was found that the incidence of blood group 0 was higher in patients with acute lymphoblastic leukemia and that the incidence of blood group A was lower in patients with Hodgkin lymphoma and non-Hodgkin lymphoma [15]. However, in the same study, there was no relationship between blood groups and the disease in acute myeloid leukemia patients [15]. In another study, there was no difference between the ABO blood group distribution in lymphoma patients and the normal population [18]. In our study, we found that the frequency of blood group 0 in MM patients was significantly lower than in the normal population. Based on this result, we have found that having blood group 0 is a protective factor for MM development compared to having other blood groups. The direct mechanism of the effect of ABO blood group system on cancer development has not been clearly elucidated in the studies conducted so far. However, there are many theories about this relationship. In many types of cancer, $\mathrm{ABO}$ gene is encoded in the region of chromosome 9q34.2 where genetic changes are common [19]. The three variant alleles (A, B and $\mathrm{O})$ of a single gene on this chromosome determine a person's blood type by encoding three different glycosyltransferase with different substrate specificities. It is known that dysregulation in ABO glycosyltransferase activity plays a key role in carcinogenesis due to its effect on cell proliferation, tumor invasion, host immune response and metastatic spread [20]. It is thought that dysregulation of the enzymatic activities 
of glycosyltransferase A and B may result in increased plasma levels of von Willebrand factor and the risk of venous thromboembolism, leading to angiogenesis, apoptosis and tumor formation [21]. These hypotheses aim to explain why the incidence of cancer is lower in blood group 0, as in our study. However, in many studies, there was no relationship between $\mathrm{ABO}$ blood group system and cancer development, or there was no significant risk reduction in cancer development in all cancer types in blood group 0 . This suggests that there are various mechanisms between the ABO blood group system and cancer development.

This study found no relationship between the ABO blood group system and common laboratory and clinical findings in MM patients such as anemia, renal failure, hypercalcemia and lytic lesions. In our study, the incidence of extramedullary lesion was $15.1 \%$ in the whole patient population. Varettoni et al. found that the prevalence of extramedullary lesion was $13 \%$, similar to our study [5]. It is not known why some people only have solitary extramedullary lesions, while some people also develop multiple myeloma. However, while some MM patients develop extramedullary lesions, the mechanism of its absence has not been explained. It is thought to be associated with the differences in cellular adhesion molecules or chemokine receptor expression profiles of malignant plasma cells [22]. Our study examined the relationship between blood groups and the incidence of extramedullary lesions in MM patients and found that having blood group 0 was a predisposing factor for extramedullary lesion development.

Serum LDH level was significantly higher in MM patients with blood group 0 compared to MM patients with other blood groups. Serum LDH levels above normal indicate that the disease will be aggressive and that the proliferation rate is high [23]. However, it has also been demonstrated that high serum LDH levels may be associated with an extramedullary lesion in MM patients [24]. In our study, we found that blood group 0 was associated with both high serum LDH levels and high prevalence of extramedullary lesions. We think that higher prevalence of extramedullary lesions in this blood group may have contributed to the significantly higher serum LDH level in blood group 0 .

Our study evaluated the prognostic significance of blood groups in MM patients. Overall survival was significantly shorter in patients with blood group 0 . These results show that $\mathrm{ABO}$ blood group has a strong prognostic value in MM patients. Osada et al. showed in their study that $\mathrm{ABO}$ blood group system had a prognostic significance in lymphoma patients [18]. However, OS was significantly shorter in patients with group B in this study. In another study of patients with pancreatic cancer, the median OS was significantly longer in patients with blood type 0 than in patients with non-0 blood groups (A, B, and AB) [25]. All these studies show that different blood groups have prognostic importance in different types of cancer.
However, the mechanism that causes this difference is unknown.

The retrospective nature of our study was the most important limiting factor. However, there was a sufficient number of patients to obtain consistent results in all blood groups.

In conclusion, individuals with blood group 0 had a lower risk of developing MM in this study. It was determined that having blood group 0 in MM patients was a predisposing factor for the development of extramedullary lesions, and that these patients had high serum LDH levels. In addition, it was shown that having blood group 0 was a very important prognostic factor for MM patients and was associated with short OS. Although there was a relationship between ABO blood group system and the development of MM and OS, additional studies are needed to explain the mechanism of this relationship.

Funding There is no source of financial support or funding.

\section{Compliance with ethical guidelines}

Conflict of interest M. Göçer and E. Kurtoğlu declare that they have no competing interests.

Ethical standards The study protocol received institutional review board approval and all patient's personal data have been secured. Approval was obtained from the hospital administration and the local ethics committee to use the patients' data. The study was conducted in accordance with the ethical principles of the Declaration of Helsinki.

\section{References}

1. Kyle RA, Gertz MA, Witzig TE, et al. Review of 1027 patients with newly diagnosed multiple myeloma. Mayo Clin Proc. 2003;78(1):21-33. https://doi.org/10.4065/78.1.21.

2. Moreau P, San Miguel J, Sonneveld P, et al. Multiple myeloma: ESMO clinical practice guidelines for diagnosis, treatment and follow-up. Ann Oncol. 2017;28:iv52-iv61. https://doi.org/10.1093/annonc/mdx096.

3. Kyle RA, Rajkumar SV. Epidemiology of the plasma-cell disorders. BestPractRes Clin Haematol. 2007;20(4):637-64. https://doi.org/10.1016/j.beha.2007.08.001.

4. Bird JM, Owen RG, D'Sa S, et al. Guidelines for the diagnosis and management of multiple myeloma 2011. Br J Haematol. 2011;154(1):32-75. https://doi.org/10.1111/j. 1365-2141.2011.08573.x.

5. Varettoni M, Corso A, Pica G, Mangiacavalli S, Pascutto C, Lazzarino M. Incidence, presenting features and outcome of extramedullary disease in multiple myeloma: a longitudinal study on 1003 consecutive patients. Ann Oncol. 2010;21(2):325-30. https://doi.org/10.1093/annonc/ mdp329.

6. Siransy LK, Nanga ZY, Zaba FS, Tufa NY, Dasse SR. ABO/rh blood groups and risk of HIV infection and hepatitis $B$ among blood donors of Abidjan, Côte D'Ivoire. Eur J Microbiol Immunol. 2015;5(3):205-9. https://doi.org/10. $1556 / 1886.2015 .00029$.

7. Lesky E. Viennese serological research about the year 1900: its contribution to the development of clinical medicine. Bull NYAcad Med. 1973;49(2):100-11. 
8. Eastlund T. The histo-blood group ABO system and tissue transplantation. Transfusion. 2003;38(10):975-88. https:// doi.org/10.1046/j.1537-2995.1998.381098440863.x.

9. Breimer ME, Mölne J, Norden G, Rydberg L, Thiel G, Svalander CT. Blood group A and B antigen expression in human kidneys correlated to A1/A2/B, Lewis, and secretor status. Transplantation. 2006;82(4):479-85. https://doi.org/10. 1097/01.tp.0000231697.15817.51.

10. Beardmore JA, Karimi-Booshehri F. ABO genes are differentially distributed in socio-economic groups in England. Nature. 1983;303(5917):522-4. https://doi.org/10.1038/ $303522 \mathrm{a} 0$.

11. Li J, Wang X, Chen J, Cai Y, Deng A, Yang M. Association between ABO blood groups and risk of SARS-CoV-2 pneumonia. Br J Haematol. 2020;190(1):24-7. https://doi.org/ 10.1111/bjh.16797.

12. Aird I, Bentall HH, Roberts JAF. A relationship between cancer of stomach and the $\mathrm{ABO}$ blood groups. $\mathrm{Br}$ Med J. 1953;1(4814):799-801. https://doi.org/10.1136/ bmj.1.4814.799.

13. Wolpin BM, Chan AT, Hartge P, et al. ABO blood group and the risk of pancreatic cancer. J Natl Cancer Inst. 2009;101(6):424-31. https://doi.org/10.1093/jnci/djp020.

14. Wang Z, Liu L, Ji J, et al. Abo blood group system and gastric cancer: a case-control study and meta-analysis. Int J Mol Sci. 2012;13(10):13308-21. https://doi.org/10.3390/ ijms 131013308 .

15. Vadivelu MK, Damodaran S, Solomon J, Rajaseharan A. Distribution of ABO blood groups in acute leukaemias and lymphomas. Ann Hematol. 2004;83(9):584-7. https://doi. org/10.1007/s00277-004-0888-1.

16. Guleria K, Singh HP, Kaur H, Sambyal V.ABOblood groups in gastrointestinal tract (GIT) and breast carcinoma patients. Anthropologist. 2005;7(3):189-92. https://doi.org/10. 1080/09720073.2005.11890905.

17. Rashaduz Z, Mohammad P, Md J, Mohammed AS. Study of $\mathrm{ABO}$ and Rh-D blood group among the common people of Chittagong city corporation area of Bangladesh. J Public Health Epidemiol. 2015;7(9):305-10. https://doi.org/10. 5897/jphe2015.0727.

18. Osada Y, Ito C, Nishiyama-Fujita Y, et al. Prognostic impact of $\mathrm{ABO}$ blood group on survival in patients with malignant lymphoma. Clin Lymphoma Myeloma Leuk.
2019;20(2):122-9. https://doi.org/10.1016/j.clml.2019.09. 607.

19. Reid ME, Mohandas N. Red blood cell blood group antigens: structureandfunction. Semin Hematol. 2004;41(2):93-117. https://doi.org/10.1053/j.seminhematol.2004.01.001.

20. Hakomori SI. Antigen structure and genetic basis of histoblood groups A, B and O: their changes associated with human cancer. Biochim Biophys Acta. 1999;1473(1):247-66. https://doi.org/10.1016/S0304-4165(99)00183-X.

21. Ohira T, Cushman M, Tsai MY, et al. ABO blood group, other riskfactors andincidence of venous thromboembolism: the longitudinal investigation of thromboembolism etiology (LITE). JThromb Haemost. 2007;5(7):1455-61. https://doi. org/10.1111/j.1538-7836.2007.02579.x.

22. Hughes M, Doig A, Soutar R. Solitary plasmacytoma and multiple myeloma: adhesion molecule and chemokine receptor expression patterns. Br J Haematol. 2007;137(5): 486-7. https:// doi.org/10.1111/j.1365-2141.2007.06599.x.

23. Palumbo A, Avet-loiseau H, Oliva S, et al. Revised international staging system for multiple myeloma: a report from international myeloma working group. J Clin Oncol. 2015;33(26):2863-9. https:// doi.org/10.1200/JCO.2015.61. 2267.

24. Barlogie B, Smallwood L, Smith T, Alexanian R. High serum levels of lactic dehydrogenase identify a high-grade lymphoma-like myeloma. Ann Intern Med. 1989;110(7):521-5. https://doi.org/10.7326/0003-4819-110-7-521.

25. Ben Q, Wang K, Yuan Y, Li Z. Pancreatic cancer incidence and outcome in relation to $\mathrm{ABO}$ blood groups among Han Chinese patients: a case-control study. Int J Cancer. 2011;128(5):1179-86. https://doi.org/10.1002/ijc.25426.

Publisher's Note Springer Nature remains neutral with regard to jurisdictional claims in published maps and institutional affiliations.

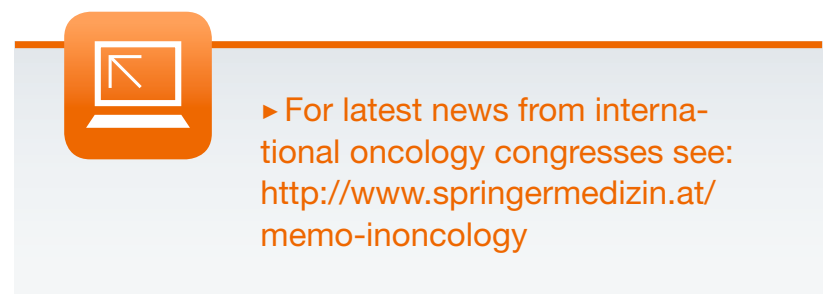

